\title{
Aortic Valve Vena Contracta Width
}

National Cancer Institute

\section{Source}

National Cancer Institute. Aortic Valve Vena Contracta Width. NCI Thesaurus. Code

C127544.

The width of the vena contracta of the aortic valve. 